\title{
A Novel Hybrid Active Power Filter with Multi-Coupled Coils
}

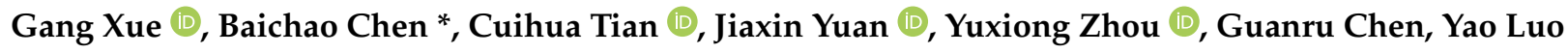 \\ and Yaojun Chen
}

check for updates

Citation: Xue, G.; Chen, B.; Tian, C.; Yuan, J.; Zhou, Y.; Chen, G.; Luo, Y.; Chen, Y. A Novel Hybrid Active Power Filter with Multi-Coupled Coils. Electronics 2021, 10, 998. https://doi.org/10.3390/ electronics10090998

Academic Editor: Khaled Ahmed

Received: 23 March 2021

Accepted: 20 April 2021

Published: 22 April 2021

Publisher's Note: MDPI stays neutral with regard to jurisdictional claims in published maps and institutional affiliations.

Copyright: (c) 2021 by the authors. Licensee MDPI, Basel, Switzerland. This article is an open access article distributed under the terms and conditions of the Creative Commons Attribution (CC BY) license (https:// creativecommons.org/licenses/by/ $4.0 /)$.
School of Electrical Engineering and Automation, Wuhan University, Wuhan 430072, China; xgelec@whu.edu.cn (G.X.); tianch@whu.edu.cn (C.T.); yuanjiaxin@whu.edu.cn (J.Y.); 2015102070007@whu.edu.cn (Y.Z.); 2019102070025@whu.edu.cn (G.C.); luoyao@whu.edu.cn (Y.L.); 2010102070023@whu.edu.cn (Y.C.)

* Correspondence: bchen@whu.edu.cn

\begin{abstract}
This paper proposes a hybrid active power filter (HAPF) with multi-coupled coils, applied to a medium- and high-voltage power grid. The passive filter of the proposed HAPF adopts the structure of multi-coupled coils to compress the traditional multiple LC branches into one branch which presents the same harmonic impedance characteristics as the former multiple LC branches. In the active power filter of the HAPF, a coupled inductor, instead of a transformer, is used to connect with the passive filter. The coupled inductor has mutual inductances with inductors of the passive filter. Through spatial magnetic coupling, the active power filter can inject compensation current into the power grid to eliminate the residual harmonics and absorb active power from the power grid to maintain the DC capacitor voltage. When the active power filter is open-circuited or short-circuited, the filtering effect of the passive filter can still be guaranteed, which improves the reliability of the filter. The benefits of the proposed HAPF with excellent harmonic filtering performance are that the inductors occupy only $1 / 3$ space as compared with traditional three-tuned LC filter, and very small power of the active power filter. The feasibility of the proposed HAPF is verified through simulations and experiment.
\end{abstract}

Keywords: harmonic distortion; hybrid active power filter; active power filter; harmonic elimination

\section{Introduction}

In the power grid, nonlinear loads result in harmonic problems: increasing the power loss in the power system, interfering with the communication network, affecting the performance of high-precision devices, etc. [1,2].

The power filter is usually used to deal with harmonic problems in the power system, which can be classified as passive filter (PF), active power filter (APF), and hybrid active power filter (HAPF). PF is widely used in the power grid because of its simple structure, low cost, and mature technology [3-5]. However, the filtering effect of PF depends on its own element parameters and the grid parameters. Besides, PF usually has large volume, large required space. Compared with PF, the filtering effect of APF is not affected by grid parameters and the control of APF is flexible [6-8]. However, standalone APF has limited capacity and high cost, which is not suitable for high-voltage and a large-capacity situation.

In order to combine the advantages of both PF (large capacity, high reliability) and APF (excellent control performance), HAPFs of various topologies were proposed, which can reduce the capacity of active power filter in the medium- and high-voltage power grid [9-22]. There are two types of HAPFs: series HAPFs and shunt HAPFs. In series HAPF, the active power filter is connected to the power grid in series using a transformer [9]. The series HAPF has good filtering performance, but the fundamental current flows through the transformer, limiting the feasibility of the practical application.

The common topologies of shunt HAPF can be divided into the following three types: 
(1) The active power filter that is in parallel with the passive filter [10,11]. In this type of topology, the active power filter is connected to the power grid through a transformer, whose volume is large. The topology is simple, but on the low-voltage side of the transformer, the current is relatively large. Besides, the output current of the active power filter may flow into the parallel PF.

(2) The active power filter that is in series with the passive filter [12-18]. In this type of topology, the active power filter can be connected in series with the passive filter directly or through a transformer. The passive filter bears most of the fundamental voltage and the fundamental voltage of the active power filter is very small. Considering that the active power filter and the passive filter are in series, once the active power filter is open-circuited, the high fundamental voltage will be applied to the transformer winding.

(3) The injection-type HAPF: the active power filter is shunted to a fundamental resonance circuit, through a matching transformer [19-22]. The injection-type HAPF can significantly reduce the fundamental voltage of the active power filter. However, the fundamental resonator has a large volume. In addition, an additional rectifier is needed to support the DC-side voltage.

The passive filter of HAPF is generally the LC filter, which is used to eliminate characteristic harmonics, such as 3rd, 5th, 7th, and 11th harmonics. Three inductors are needed for each phase to eliminate 5th, 7th, and 11th harmonics, so, for three phases, nine inductors are needed. These inductors are usually arranged separately (straight-line shape, triangle, etc.) to eliminate the effect of mutual inductances. Thus, these inductors would occupy a large area. The conventional dry-type air core reactor also has a stacking mode, but in order to eliminate mutual inductances and other reasons, the stacking mode will significantly raise the center of gravity of the reactor as a whole, increasing the requirements for the safety design of structural accessories.

Authors developed a new method for calculating the inductance of air-core circular coils with rectangular cross section and parallel axes [23,24]. Moreover, a compact multituned filter with coupled inductors was proposed in [5], which can reduce the required space of inductors while eliminating characteristic harmonics. However, this structure still has other inherent problems of conventional passive filters (detuning, resonance, etc.).

Based on this, this paper proposes a novel hybrid active power filter (HAPF) with multi-coupled coils. The passive filter of the HAPF uses a multi-coupled coils structure, and the design method of the multi-coupled coils is the same as [5]. The active power filter of the HAPF includes an active converter and a coupled inductor. Mutual inductances exist between the coupled inductor and each coil of the passive filter. The active power filter is connected with the passive filter through the coupled inductor.

In hybrid compensation, the converter generates a current on the coupled inductor. Then, this output current will be injected into the passive filter branch through spatial magnetic coupling to eliminate the residual harmonics. At the same time, the active converter would absorb the active power from the grid to maintain the DC capacitor voltage. The coupled inductor of the active power filter is closest to the main coil of the passive filter, which can obtain a high coupling coefficient.

The proposed HAPF topology in this paper has two distinct innovations:

(1) The multi-coupled coils used in the passive filter of the HAPF compress the traditional multiple LC branches into one branch which presents the same harmonic impedance characteristics as the former multiple LC branches. The inductors occupy only $1 / 3$ of the space as compared with the traditional three-tuned LC filter.

(2) A coupled inductor, instead of a transformer, is used in the active power filter of the HAPF to connect with the passive filter. When the active power filter is open-circuited or short-circuited (even if the protection does not work and not cut off from the active power filter), the filtering effect of the passive filter can still be guaranteed. The capacity of the active power filter in the proposed HAPF is small. 
This paper is structured as follows: Firstly, the structure of the proposed HAPF is introduced. Secondly, the working principle of the HAPF is analyzed. Thirdly, the control strategy of hybrid compensation is proposed. Then, the effectiveness of the control strategy is verified through simulations. At last, an experimental platform is built and the feasibility of the HAPF is verified by experiments.

\section{Main Circuit}

\subsection{Passive Filter with Multi-Coupled Coils}

The passive filter of the proposed HAPF is shown in Figure 1. Figure 1a represents the schematic diagram of a three-tuned passive filter with multi-coupled coils. In Figure 1a, $i_{L}$ is the load current, $i_{S}$ is the supply current, and $i_{f}$ is the filter branch current. $C_{3}, C_{4}$, and $C_{5}$ are the capacitors in passive filter. $L_{1}, L_{2}, L_{3}, L_{4}$, and $L_{5}$ are the inductors in the passive filter.

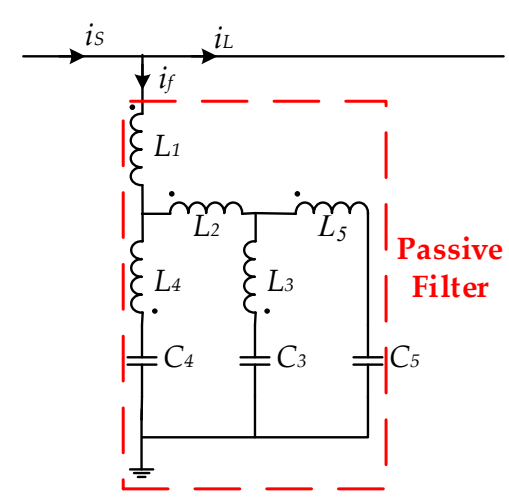

(a)

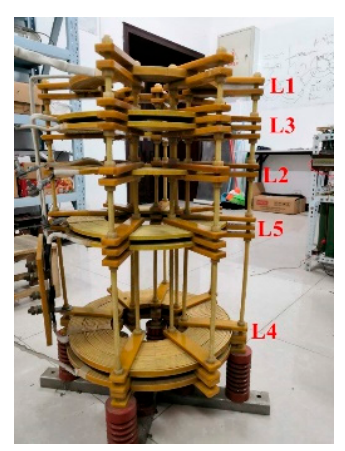

(b)

Figure 1. Passive filter of HAPF with multi-coupled coils. (a) Schematic diagram of the passive filter. (b) Prototype of multi-coupled coils.

$L_{1}, L_{2}, L_{3}, L_{4}, L_{5}$ have mutual inductances among one another, which is the biggest difference between the passive filter in the proposed HAPF and the conventional multituned LC filter. Conventional multi-tuned LC filters ignore the coupling effect between the inductors. To ensure this, the inductors in conventional multi-tuned LC filters need to be arranged separately, resulting in a large required space.

In this paper, a prototype of multi-coupled coils has been designed and manufactured, which is shown in Figure 1b, according to the design process in [5]. There are mutual inductances among the inductors. The multi-coupled coils are designed as a layered structure of multiple coaxial round wire discs, whose required space is reduced. For a set of the n-tuned filter, the required space of the multi-coupled coils is about $1 / \mathrm{n}$ of the required space of inductors in the traditional passive filter. At present, the capacity of actually manufactured multi-coupled coils ranges from dozens of kvar to several Mvar.

However, the requirements for assembly of the passive filter with multi-coupled coils in Figure $1 b$ are higher than that of the traditional LC filter. In this structure, the number of coil turns determines the self-inductance. Moreover, the number of coil turns and the relative positions of the coils determine the mutual inductances together. Therefore, an accurate installation of this structure is crucial for obtaining the required parameters.

The passive filter with multi-coupled coils also has the inherent drawbacks of the conventional passive filter. The filtering effect of the passive filter can be affected by the grid parameters. In severe cases, the passive filter may resonate at a certain frequency. According to the design principle of the passive filter, considering the frequency offset in the power grid and the equipment manufacturing error, the tuned frequency of the passive filter should be set 3-15\% lower than the characteristic frequency [25]. 
Therefore, on the basis of the passive filter with multi-coupled coils, this paper also connects an active filter to the passive filter via a coupled inductor, to eliminate the remaining harmonic current after passive compensation.

\subsection{Deign of the Passive Filter with Multi-Coupled Coils}

In the passive filter with multi-coupled coils, there are mutual inductances among the inductors. Therefore, in the design process, the self-inductances and mutual inductances need to be calculated and designed [5]. The basic design flow chart is shown in Figure 2.

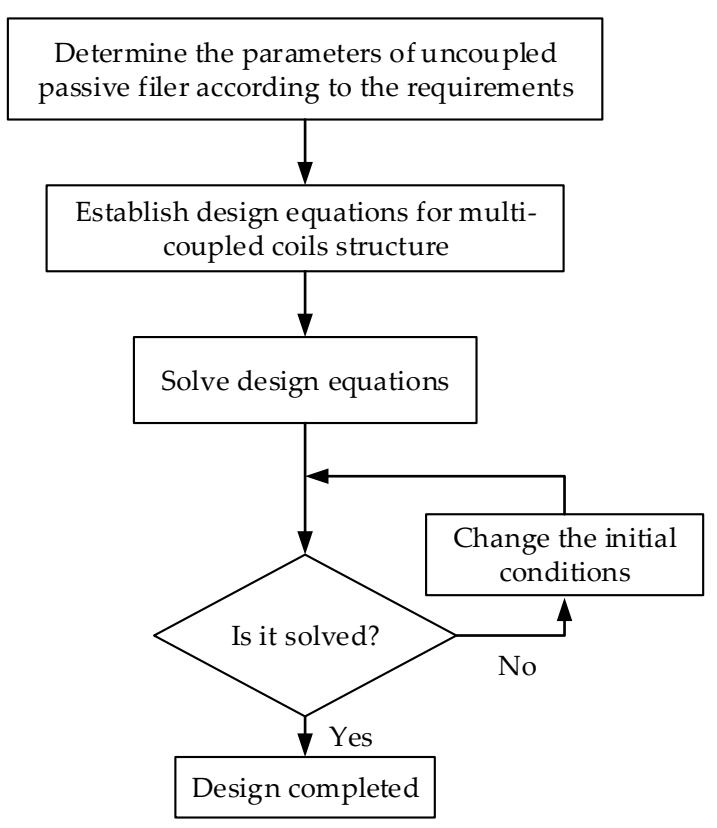

Figure 2. Basic design flow chart of the passive filer with multi-coupled coils structure.

According to Figure 2, the first step of the design process is to determine the parameters of the uncoupled passive filter considering the rated voltage, capacity. One type of uncoupled passive filter is shown in Figure 3a. In Figure 3a, the inductors $L_{a}, L_{b}, L_{c}$ and the capacitors $C_{3}, C_{4}, C_{5}$ are determined in this step.

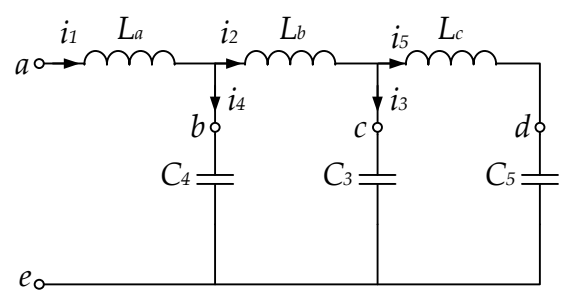

(a)

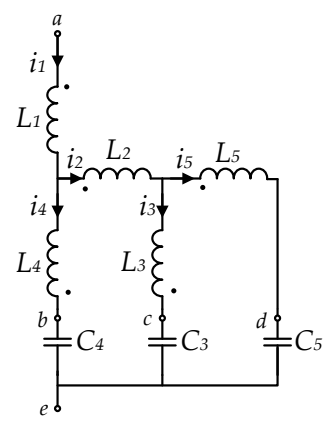

(b)

Figure 3. Passive filter. (a) Cauer I form three-tuned filter circuit. (b) Passive filter with multicoupled coils.

The second step is to establish the design equations for the multi-coupled coils structure. Figure $3 \mathrm{~b}$ shows the passive filter with multi-coupled coils. In Figure $3 \mathrm{a}, \mathrm{b}$, the values of capacitor $C_{3}, C_{4}, C_{5}$ are the same. To make the network shown in Figure $3 \mathrm{~b}$ equivalent to the network in Figure 3a, it is necessary to ensure that when the two networks have 
the same excitation, the voltages at point $\mathrm{a}, \mathrm{b}, \mathrm{c}, \mathrm{d}$ and the current $i_{1}, i_{2}, i_{3}, i_{4}, i_{5}$ in the two figures are the same. Moreover, according to this relationship, formulas are as follows:

$$
\begin{gathered}
L_{1}-2 M_{14}+L_{4}=L_{\mathrm{a}} \\
-L_{4}+M_{12}-M_{13}+M_{14}-M_{24}+M_{34}=0 \\
M_{13}+M_{15}-M_{34}-M_{45}=0 \\
L_{2}+L_{3}+L_{4}+2 M_{24}-2 M_{34}-2 M_{23}=L_{\mathrm{b}} \\
-L_{3}+M_{23}+M_{25}+M_{34}-M_{35}+M_{45}=0 \\
L_{3}+L_{5}+2 M_{35}=L_{\mathrm{c}}
\end{gathered}
$$

in which, $L_{1}, L_{2}, L_{3}, L_{4}, L_{5}$ are the self-inductances of the inductors in the passive filter with multi-coupled coils; $M_{i j}$ is the mutual inductance between $L_{i}$ and $L_{j}(i, j=1,2,3$, $4,5$ and $i \neq j) ; L_{a}, L_{b}, L_{c}$ are the self-inductances of the inductors in the Cauer I form three-tuned filter.

In (1)-(6), the self-inductances $L_{1}, L_{2}, L_{3}, L_{4}, L_{5}$ and the mutual inductances $M_{12}$, $M_{13}, M_{14}, M_{15}, M_{23}, M_{24}, M_{25}, M_{34}, M_{35}, M_{45}$ are unknown quantities. Since the multicoupled coils are designed as a layered structure of multiple coaxial round wire discs, the number of turns of each coil $\left(N_{1}, N_{2}, N_{3}, N_{4}, N_{5}\right)$ and the relative position between the coils $\left(d_{1}, d_{2}, d_{3}, d_{4}, d_{5}\right)$ determine the self-inductances and mutual inductances of the coils. Thus, (1)-(6) can be converted into equations about the number of coil turns $\left(N_{1}, N_{2}, N_{3}\right.$, $\left.N_{4}, N_{5}\right)$ and the relative positions of the coils $\left(d_{1}, d_{2}, d_{3}, d_{4}, d_{5}\right)$. There are 6 equations and 10 unknowns. Therefore, initial conditions are needed. We can set the position $d_{1}$ of inductor $L_{1}$, and set the coil turn $N_{1}$ of $L_{1}$ according to the value of $L_{a}$. Two mutual inductance relationships (such as: $M_{12}=M_{13}, M_{34}=M_{35}$ ) can be added. In this way, there are 8 equations and 8 unknowns, and the design equation set of the multi-coupled coils structure can be obtained.

The third step is to solve the nonlinear equations. The unknowns in the aforementioned equations can be worked out using the inductance calculation formula in $[23,24]$. If the nonlinear equations cannot be solved, the initial conditions shall be changed. In this way, the number of coil turns and the relative positions of the coils can be obtained. The passive filter with multi-coupled coils can be designed.

\subsection{Structure of the HAPF with Multi-Coupled Coils}

The topology of the HAPF with multi-coupled coils is shown in Figure 4, in which an active power filter is added to the passive filter. The active power filter consists of an H-bridge converter and a LCL filter. The inductor $L_{g}$ of the LCL filter is the coupled inductor of the active power filter.

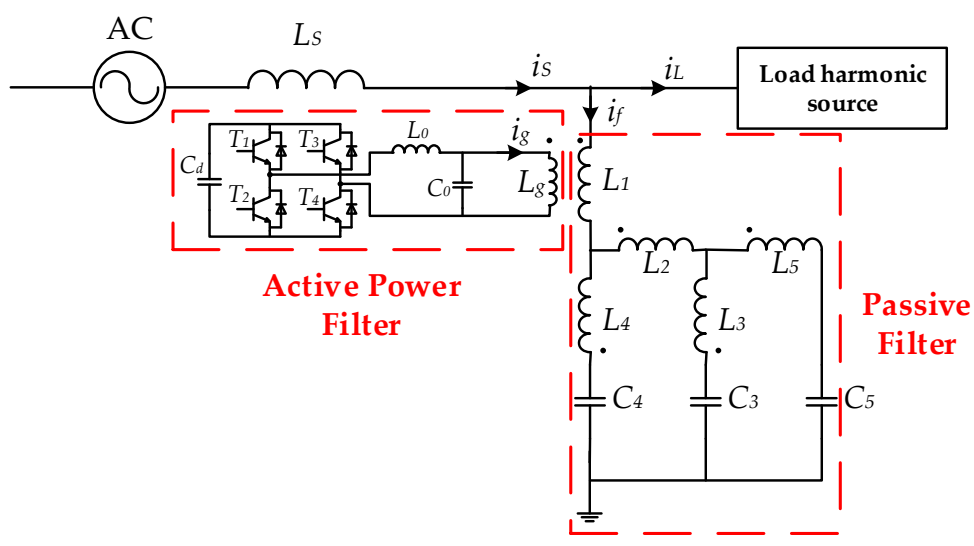

Figure 4. Topology of novel HAPF with multi-coupled coils. 
There are mutual inductances between the coupled inductor $L_{g}$ and the inductors in the passive filter. The coupled inductor $L_{g}$ is closest to inductor $L_{1}$ and most closely coupled with $L_{1}$. When the active power filter works, the converter generates a controllable AC current $i_{g}$ to the coupled inductor $L_{g}$. Since the spatial magnetic coupling exists among $L_{g}$ and the inductors in the passive filter, a current can be injected into the passive filter branch, thereby changing the current of the passive filter branch $i_{f}$. Thus, the remaining characteristic harmonic currents after passive compensation can be eliminated.

Compared with the conventional shunt HAPF topology, the proposed HAPF has the similar current compensation principle. The passive filter of the proposed HAPF bears the fundamental voltage and eliminates most of the characteristic harmonic currents. The active power filter bears a very small fundamental voltage and eliminates the remaining harmonic currents.

In the proposed HAPF, the connection mode of the active power filter and the passive filter is different from the traditional HAPF. For the traditional HAPF topology in which the active power filter is in series with the passive filter through a transformer, the series connection of the transformer changes the filter loop of the passive filter. In Figure 4, the active power filter of the proposed HAPF connects with the passive filter through spatial magnetic coupling instead of a transformer. The coupled inductor $L_{g}$ is designed as a round wire disc, which is placed very close to the multi-coupled coils in the passive filter. The coupled inductor $L_{g}$ is not directly connected in series to the filter loop of the passive filter. So, the coupled inductor $L_{g}$ does not change the filter loop of the passive filter. Compared to a transformer, the cost of the coupled inductor $L_{g}$ in Figure 4 is relatively small in the entire HAPF. This connection mode ensures that whether the active converter is open-circuited or short-circuited, the filtering effect of the passive filter always exists and the safety of the power grid will not be at stake. Besides, the coaxial round wire discs inductor structure can enhance the coupling effect and increase the overall efficiency of the system.

\section{Working Principle}

The equivalent schematic of the hybrid compensation of the proposed HAPF is shown in Figure 5, where $u_{1}$ to $u_{5}$ are the induced voltages controlled by the output current $i_{g}$ of the converter through spatial magnetic coupling and $u_{g}$ is the voltage source controlled by all the currents of the passive filter.

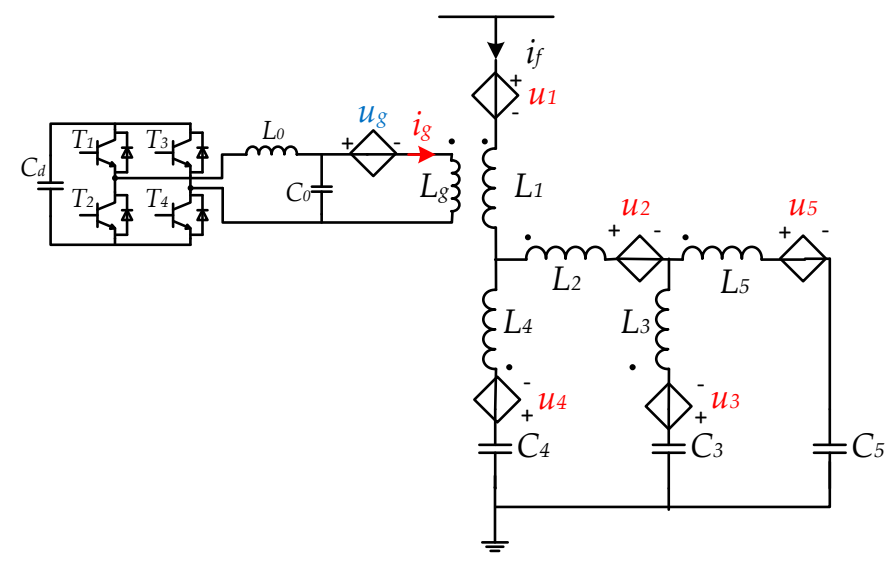

Figure 5. Equivalent schematic of the hybrid compensation.

Because the coupled inductor $L_{g}$ is placed above the multi-coupled coils, it is closest to inductor $L_{1}$, which is at the top of the multi-coupled coils. So, the mutual inductance $M_{g 1}$ between $L_{g}$ and $L_{1}$ is relatively large, and the effect of the induced voltage source $u_{1}$ is relatively large. For an inductor that is relatively far from $L_{g}$ in space, the mutual inductance between it and $L_{g}$ will be much smaller than $M_{g 1}$.

The self-inductance and mutual inductance of each coil in Figure $1 \mathrm{~b}$ were measured. The measurement results show that the mutual inductance $M_{g 1}$ (between $L_{1}$ and $L_{g}$ ) and 
$M_{g 3}$ (between $L_{3}$ and $L_{g}$ ) are much larger than $M_{g 2}$ (between $L_{2}$ and $L_{g}$ ), $M_{g 4}$ (between $L_{4}$ and $L_{g}$ ), and $M_{85}$ (between $L_{5}$ and $L_{g}$ ). Therefore, to simplify the theoretical analysis, the mutual inductance $M_{g 2}, M_{g 3}, M_{g 4}, M_{g 5}$ are combined to an equivalent inductance $M_{g^{\prime}}$ in Figure 6, where $u^{\prime}$ represents the equivalent induced voltage source generated in the filter branch by $M_{g^{\prime}}$. For the characteristic harmonic, the impedance of the passive filter branch is very small. $L_{t h}$ and $R_{t h}$ represent the equivalent inductance and resistance of the passive filter branch at harmonic frequencies, respectively. $L_{S}$ and $R_{S}$ represent the supply-system inductance and resistance, respectively.

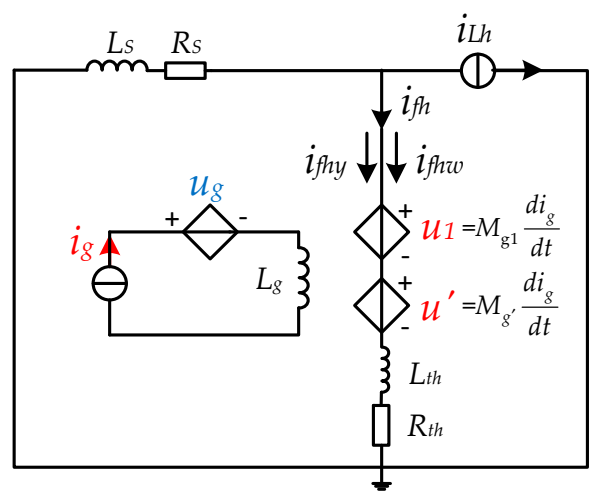

Figure 6. Simplified schematic of hybrid compensation.

The current $i_{f h}$ represents the harmonic component of the filter branch current $i_{f}$. The current $i_{f h w}$ represents the passive current component of $i_{f h}$, which is the harmonic component when only the passive filter works; the current $i_{\text {fhy }}$ represents the injected current component of $i_{f h}$ by the active power filter. $i_{L h}$ is the harmonic component of the load current $i_{L}$. Figure 6 is only used to simplify the theoretical analysis.

According to Figure 6 , the induced voltage $u_{1}$ and $u^{\prime}$ caused by $i_{g}$ can generate the injected current $i_{f h y}$ on the passive filter branch. In the harmonic current loop, $L_{t h}, R_{t h}, L_{s}$, and $R_{s}$ will affect the value of $i_{f h y}$.

At tuned frequencies, series resonance occurs in the passive filter branch and the values of $L_{t h}$ and $R_{t h}$ are very small. Therefore, at tuned frequencies, the current $i_{g}$ can produce a relatively large $i_{f h y}$. By controlling the output current $i_{g}$ of the active power filter, the injected current component $i_{f h y}$ of $i_{f h}$ can be adjusted, then so can the harmonic $i_{f h}$.

As long as the active power filter generates a current $i_{g}$ of a certain frequency, the injected current $i_{f h y}$ of corresponding frequency will be generated on the passive filter branch. Besides the tuned frequencies, the active power filter in the proposed HAPF can also filter harmonic currents at other frequencies. However, at these frequencies, the values of $L_{t h}$ and $R_{t h}$ are relatively large. Therefore, the current $i_{f h y}$ generated on the passive filter branch with the same magnitude of current $i_{g}$ will be relatively smaller than that generated at the tuned frequency.

When the amplitude of each characteristic harmonics of $i_{f h}$ and $i_{L h}$ are the same, and the phases are opposite, the harmonics in the supply current $i_{S}$ can be completely eliminated.

\section{Control Strategy}

When the active power filter of the proposed HAPF works, the accurate harmonic current tracking control is needed, as well as the capacitor voltage control on the DC side of the active converter. Therefore, the control block diagram of hybrid compensation is shown in Figure 7, which consists of three parts: DC voltage control module, current tracking control module, and current hysteresis control module. 


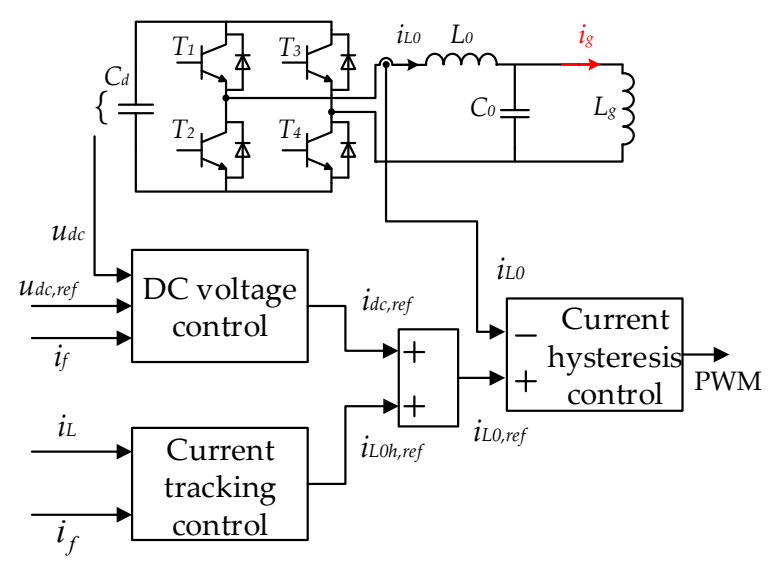

Figure 7. The control block diagram of hybrid compensation.

The DC voltage control module is used to stabilize the DC capacitor voltage. The output of the DC voltage control module is $i_{d c, r e f}$, which represents the reference value of the active current exchanged between the converter and the grid.

The current tracking control module is used to make the filter branch current accurately track the load harmonic current. The output of the current tracking control module is $i_{L 0 h, \text { ref }}$.

The sum of $i_{d c, \text { ref }}$ and $i_{L O h, \text { ref }}$ is $i_{L 0, \text { ref }}$, which is the input of the current hysteresis control module. The output of the current hysteresis control module is the PWM control signal of the active converter. The current hysteresis control can directly track the current at high speed, so the converter can be considered as a current source.

\subsection{Capacitor Voltage Control}

The stability of DC capacitor voltage is the prerequisite for the proposed HAPF to work stably. In order to maintain a stable DC capacitor voltage, it is necessary for the active converter to exchange active power with the induced voltage source $u_{g}$.

Current $i_{d c}$ is the active current, which is the active component of $i_{L 0}$. If the phase of $i_{d c}$ is the same as the phase of $u_{g}$, the converter absorbs active power from $u_{g}$, to support the DC capacitor voltage. If the phase of $i_{d c}$ is opposite to the phase of $u_{g}$, the converter exports active power to $u_{g}$. So, in Figure 8 , it is critical to properly set the amplitude and phase of $i_{d c, r e f}$, which is the reference value of $i_{d c}$.

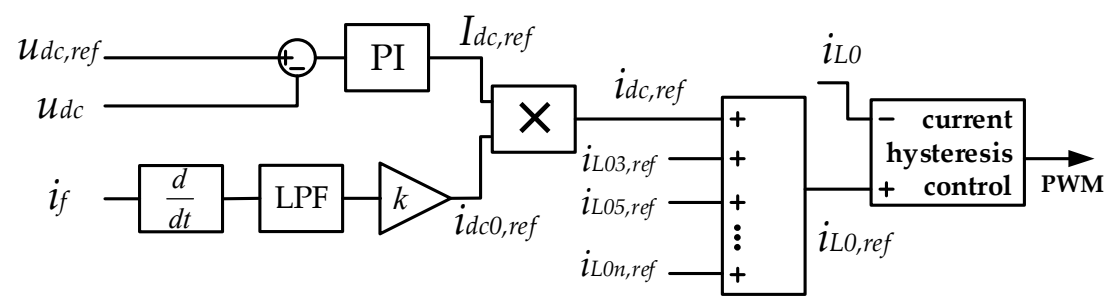

Figure 8. DC capacitor voltage control block diagram.

To obtain the amplitude $I_{d c, \text { ref }}$ of current $i_{d c, \text { ref }}$, in Figure 8, the DC capacitor voltage $u_{d c}$ is compared with the reference value $u_{d c, \text { ref, }}$ and the comparison result is sent to the PI controller. The output of the PI controller is $I_{d c, r e f}$.

The induced voltage $u_{g}$ cannot be measured directly, and it is controlled by all the currents in the passive filter. Since the coupled inductor $L_{g}$ is closest to inductor $L_{1}$ and the most closely coupled with $L_{1}$, only the filter branch current $i_{f}$ (the current on inductor $L_{1}$ ) is considered here. Then, $u_{g}$ can be expressed as:

$$
u_{g}=M_{g 1} \frac{d i_{f}}{d t}
$$


where, $M_{g 1}$ is the mutual inductance between the coupled inductor $L_{g}$ and inductor $L_{1}$.

So, according to (7), a unit signal $i_{d c 0, \text { ref }}$, which has the same waveform with $u_{g}$, can be obtained by current derivation, LPF, and waveform normalization in Figure 8 . By multiplying $i_{d c 0, \text { ref }}$ to $I_{d c, r e f}$, the reference current $i_{d c, \text { ref }}$ of the active current $i_{d c}$ can be obtained.

Considering the $3 \mathrm{rd}, 5 \mathrm{th}, 7 \mathrm{th}, 11$ th harmonic components of $i_{d c}$, the active current $i_{d c}$ can be expressed as:

$$
i_{d c}=I_{d c, r e f} \sum_{n=1,3,5,7,11} a_{n} \sin \left(n \omega t+\theta_{n}\right)
$$

where, $a_{n}$ is the amplitude of each harmonic component of the unit signal $i_{d c 0, \text { ref }}$.

When the phase of $i_{d c}$ is the same with $u_{g}, u_{g}$ can be expressed as:

$$
u_{g}=U_{g} \sum_{n=1,3,5,7,11} a_{n} \sin \left(n \omega t+\theta_{n}\right)
$$

The instantaneous power that $u_{g}$ exports is:

$$
p=U_{g} I_{d c, r e f} \sum_{n=1,3,5,7,11} \frac{a_{n}^{2}}{2}+p_{a c}
$$

where, $p_{a c}$ is the $\mathrm{AC}$ component, which represents the reactive power. Additionally, the DC component in (10) represents the active power, which is influenced by $I_{d c \text {, ref. }}$ Therefore, in DC capacitor voltage control, by controlling $I_{d c, \text { ref }}$, the active power exchanged between the converter and $u_{g}$ can be adjusted to support the DC capacitor voltage. In addition, from (10), it can be seen that the active power is provided by the fundamental and harmonic components in $u_{g}$ together.

\subsection{Harmonic Current Control}

For harmonic current elimination, at the characteristic frequencies, the amplitude and phase of the output current $i_{g}$ are controlled to track the harmonic current.

Taking $\mathrm{n}^{\text {th }}$ load harmonic as an example, current $i_{f h n}, i_{f h w n}, i_{f h y n}, i_{L h n}$, and $i_{g n}$ are the $\mathrm{n}^{\text {th }}$ component of current $i_{f h}, i_{f h w}, i_{f h y}, i_{L h}$, and $i_{g}$, respectively. According to Figure 6, current $i_{\text {fhn }}, i_{\text {fhwn }}, i_{\text {fhyn }}$ can be expressed with phasor method as:

$$
\begin{gathered}
I_{f h n} \angle \theta_{f h n}=I_{f h w n} \angle \theta_{f h w n}+I_{f h y n} \angle \theta_{f h y n} \\
I_{f h w n} \angle \theta_{f h w n}=\frac{-\left(R_{s}+j n \omega L_{s}\right)}{R_{t h}+R_{s}+j n \omega\left(L_{t h}+L_{s}\right)} \cdot I_{L h n} \angle \theta_{\text {Lhn }} \\
I_{\text {fhyn }} \angle \theta_{\text {fhyn }}=\frac{-j n \omega\left(M_{g 1}+M_{g^{\prime}}\right)}{R_{t h}+R_{s}+j n \omega\left(L_{t h}+L_{s}\right)} \cdot I_{g n} \angle \theta_{g n}
\end{gathered}
$$

where, $I_{f h n}, I_{f h w n}, I_{f h y n}, I_{L h n}, I_{g n}$ are the amplitude of $i_{f h n}, i_{f h w n}, i_{f h y n}, i_{L h n}$, and $i_{g n}$, respectively. $\theta_{f h n}, \theta_{f h w n}, \theta_{f h y n}, \theta_{L h n}, \theta_{g n}$ are the phase angles of $i_{f h n}, i_{f h w n}, i_{f h y n}, i_{L h n}$, and $i_{g n}$, respectively.

When the $\mathrm{n}^{\text {th }}$ load harmonic current $i_{L h n}$ is completely eliminated, we have the following relationship:

$$
I_{f h n} \angle \theta_{f h n}+I_{L h n} \angle \theta_{\text {Lhn }}=0
$$

Substituting (11)-(13) into (14) results in:

$$
Z_{t h n} I_{L h n} \angle\left(\theta_{L h n}+\theta_{t h n}\right)=n \omega M I_{g n} \angle\left(\theta_{g n}+90^{\circ}\right)
$$

where, $Z_{t h n}=\sqrt{R_{t h}^{2}+\left(n \omega L_{t h}\right)^{2}}, \theta_{t h n}=\arctan \frac{n \omega L_{t h}}{R_{t h}}, M=M_{g 1}+M_{g^{\prime}}$.

In (15), the amplitude $I_{g n}$ and phase angle $\theta_{g n}$ of current $i_{g n}$ are adjustable. When the $\mathrm{n}^{\text {th }}$ load harmonic current $i_{L h n}$ is definite, there is a unique $I_{g n}$ and a unique $\theta_{g n}$ that suit Equation (15). 
From (15), $I_{g n}$ and $\theta_{g n}$ should be:

$$
\begin{gathered}
I_{g n}=\frac{Z_{t h n} I_{L h n}}{n \omega\left(M_{g 1}+M_{g^{\prime}}\right)} \\
\theta_{g n}=\theta_{L h n}+\theta_{t h n}-90^{\circ}
\end{gathered}
$$

According to (16) and (17), $I_{g n}$ and $\theta_{g n}$ are only related to $\mathrm{n}^{\text {th }}$ load harmonic current $i_{L h n}$. Therefore, in theory, the $\mathrm{n}^{\text {th }}$ harmonic current $i_{L h n}$ can be completely eliminated by controlling the amplitude and phase angle of the output current $i_{g n}$ of the active power filter.

Consequently, the active power filter is controlled as an adjustable current source. Each characteristic harmonic $i_{g n}$ of output current $i_{g}$ is controlled individually. Through joint control of the amplitude and phase of $i_{g n}$, each characteristic harmonic $i_{f h n}$ of the filter branch current $i_{f}$ can be adjusted, thereby eliminating the load harmonic current $i_{L h}$.

As shown in Figure 9, the amplitude and phase of each characteristic harmonic component of the load current $i_{L}$ and filter branch current $i_{f}$ can be obtained by FFT. The amplitudes and phases obtained from $i_{L}$ are reference values. The amplitudes and phases obtained from $i_{f}$ are feedback signals.
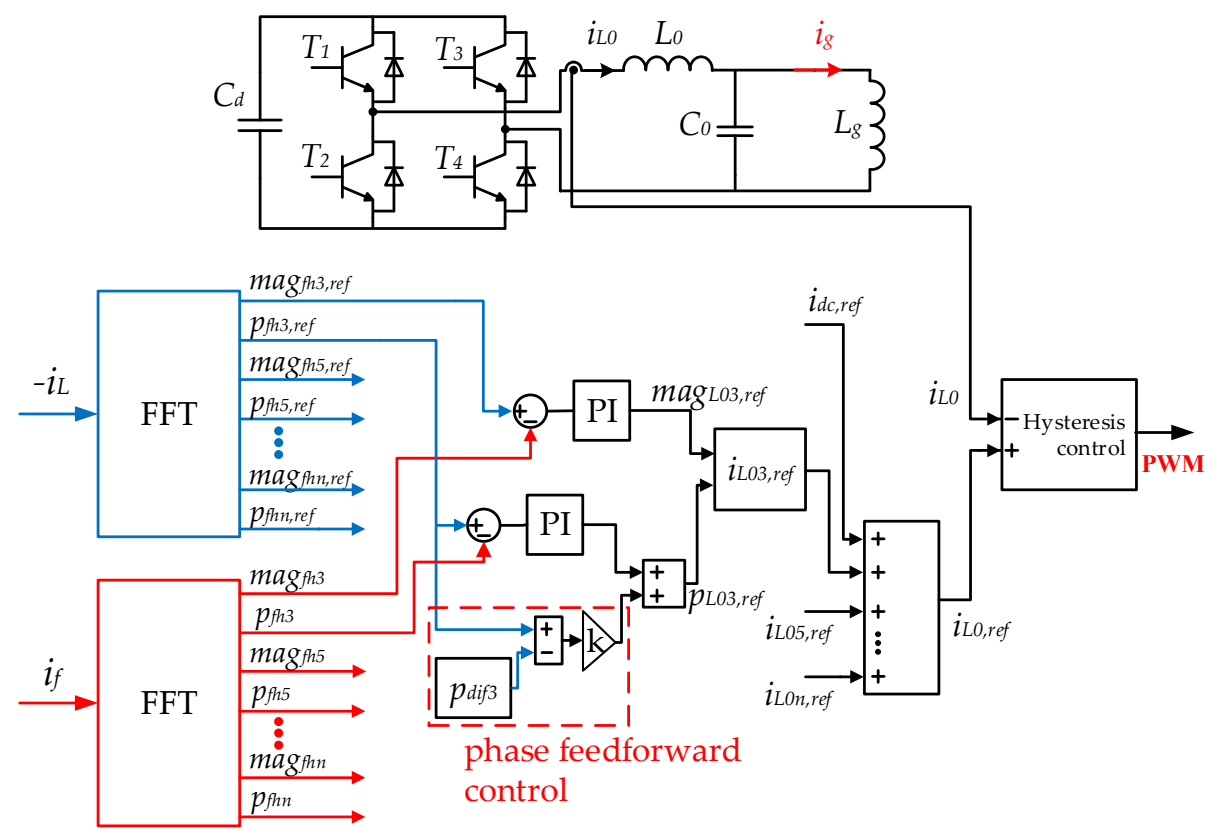

Figure 9. Block diagram of harmonic current control strategy.

These reference values and feedback signals are sent to their respective PI controllers, and then synthesized to obtain the reference signal for hysteresis control. Finally, the PWM control signal of the active converter is obtained. The hysteresis control can track the current $i_{L 0}$ well and the active power filter can generate the desired current $i_{g}$. In this paper, the width of the hysteresis band is $0.2 \mathrm{~A}$.

In order to improve response speed, the phase feedforward control is adopted, which is shown in Figure 9. In the phase feedforward control, $p_{\text {dif }}$ is the phase response with the 3rd harmonic of $i_{L 0}$ as the excitation and the 3 rd harmonic of current $i_{f}$ as the output. $k$ is the coefficient of the phase feedforward control, whose value is slightly less than 1 . The phase response can be obtained through simulation, and its value does not need to be precise.

\section{Simulation Results}

In order to verify the effectiveness of the proposed scheme, simulations of a singlephase $10 \mathrm{kV}$ hybrid active power filter with multi-coupled coils, which is shown in Figure 4, 
are carried out in MATLAB/Simulink. The load harmonic source includes 5th, 7th, and 11th harmonic current. The inductance parameters and capacitance parameters of the multi-coupled coils are calculated according to the method in [5]. The main simulation parameters except for the inductance parameters of the multi-coupled coils are shown in Table 1.

Table 1. Main simulation parameters.

\begin{tabular}{ccc}
\hline Categories & Variables & Value \\
\hline Supply-system parameters & voltage & $10 \mathrm{kV}$ \\
& frequency & $50 \mathrm{~Hz}$ \\
& $L_{S}$ & $1.2 \mathrm{mH}$ \\
\hline Load harmonic parameters & amplitude of 5 th harmonic & $40 \mathrm{~A}$ \\
& amplitude of 7 th harmonic & $30 \mathrm{~A}$ \\
& amplitude of 11 th harmonic & $20 \mathrm{~A}$ \\
\hline Converter parameters & $L_{0}$ & $0.8 \mathrm{mH}$ \\
& $C_{0}$ & $6 \mu \mathrm{F}$ \\
Passive filter parameters & $C_{d c}$ & $4700 \mu \mathrm{F}$ \\
& $u_{d c}$ & $800 \mathrm{~V}$ \\
\hline
\end{tabular}

The inductance matrix of the multi-coupled coils is shown in Table 2.

Table 2. Inductance matrix of $10 \mathrm{kV}$ HAPF with multi-coupled coils.

\begin{tabular}{ccccccc}
\hline Inductance $/ \boldsymbol{\mu H}$ & $\boldsymbol{L}_{\boldsymbol{g}}$ & $\boldsymbol{L}_{\mathbf{1}}$ & $\boldsymbol{L}_{\mathbf{2}}$ & $\boldsymbol{L}_{\mathbf{3}}$ & $\boldsymbol{L}_{\mathbf{4}}$ & $\boldsymbol{L}_{\mathbf{5}}$ \\
\hline$L_{g}$ & 4088 & 1061 & 103 & 1578 & 116 & 109 \\
$L_{1}$ & 1061 & 813 & 61 & 1047 & 60 & 62 \\
$L_{2}$ & 103 & 61 & 800 & 721 & 330 & 662 \\
$L_{3}$ & 1578 & 1047 & 721 & 10793 & 557 & 695 \\
$L_{4}$ & 116 & 60 & 330 & 557 & 7364 & 547 \\
$L_{5}$ & 109 & 62 & 662 & 695 & 547 & 1168 \\
\hline
\end{tabular}

According to the inductance and capacitance parameters in Tables 1 and 2, the impedancefrequency characteristic of the passive filter is simulated as shown in Figure 10.

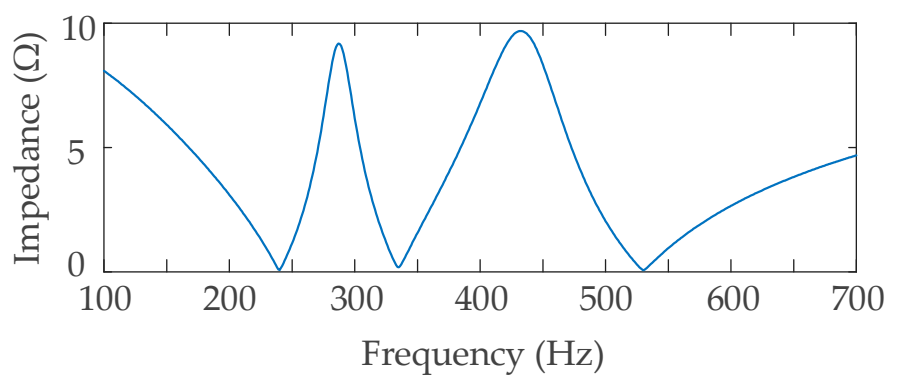

Figure 10. Impedance-frequency characteristic of the passive filter.

Figure 10 shows the tuned frequencies of the passive filter deviate from $250 \mathrm{~Hz}, 350 \mathrm{~Hz}$, and $550 \mathrm{~Hz}$ (line frequency is $50 \mathrm{~Hz}$ in China). So, the passive filter is unable to completely eliminate the 5 th, 7 th, and 11 th characteristic harmonics.

To improve the filtering effect of the passive filter, the active power filter generates current $i_{g}$ to compensate the remaining harmonic currents. In the hybrid compensation simulations, the control strategy shown in Figures 7-9 is used. 


\subsection{Current Compensation Effect}

Figure 11 shows the waveforms of supply current $i_{S}$ under different compensation strategies. The waveform of $i_{S}$ without any compensation is shown in Figure 11a. The waveform of $i_{S}$ with passive compensation is shown in Figure 11b. The waveform of $i_{S}$ with hybrid compensation is shown in Figure 11c.

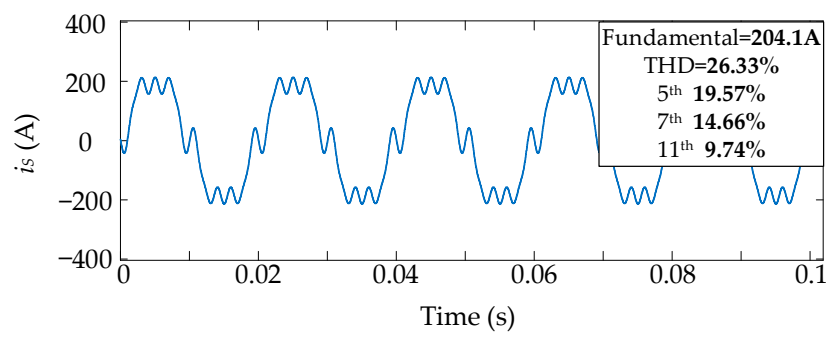

(a)

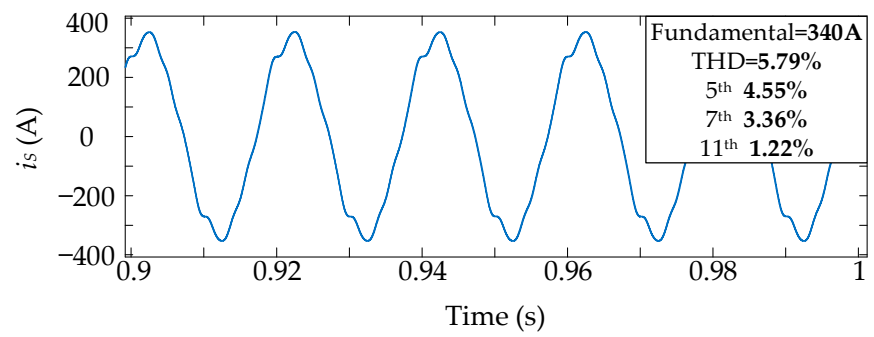

(b)

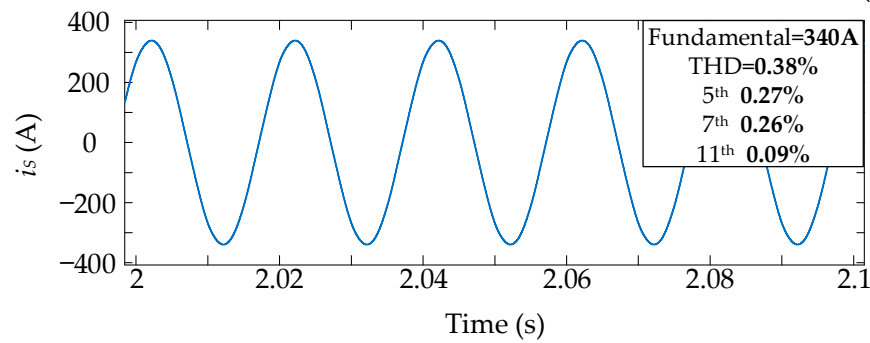

(c)

Figure 11. Supply current $i_{S}$. (a) Supply current $i_{S}$ without any compensation. (b) Supply current $i_{S}$ when only the passive filter works. (c) Supply current $i_{S}$ with hybrid compensation.

From Figure 11a, it can be seen that without any compensation, the total harmonic distortion (THD) of $i_{S}$ is $26.33 \%$. Further, the distortion of 5 th, 7 th, and 11 th harmonics of $i_{S}$ are $19.57 \%, 14.66 \%$, and $9.74 \%$, respectively. From Figure $11 \mathrm{~b}$, it can be seen that with passive compensation, the THD of $i_{S}$ is reduced to $5.79 \%$. Further, the distortion of 5 th, 7 th, and 11 th harmonics are $4.55 \%, 3.36 \%$, and $1.22 \%$, respectively. From Figure 11c, it can be seen that the THD of $i_{S}$ is reduced to $0.38 \%$. The distortion of 5 th, 7 th, and 11 th harmonics are $0.27 \%, 0.26 \%$, and $0.09 \%$, respectively.

In addition, it can be seen that in Figure 11a, the amplitude of the fundamental component of $i_{S}$ is $204.1 \mathrm{~A}$. While in Figure $11 \mathrm{~b}, \mathrm{c}$, the amplitude of the fundamental component of $i_{S}$ is $340 \mathrm{~A}$, which is larger. The reason is that after the passive filter works, the capacitive fundamental current increases, which can compensate the inductive current in the grid.

\subsection{Compensation Characteristic Simulation}

In hybrid compensation, the stability of DC capacitor voltage is the prerequisite. The output current $i_{g}$ will directly change the filter branch current $i_{f}$ and affect the filtering effect.

In order to study the compensation characteristic, Figure $12 \mathrm{a}-\mathrm{c}$ shows the waveform of the output current $i_{g}$ of the active power filter, the waveform of the filter branch current $i_{f}$, and the waveform of the DC capacitor voltage $u_{d c}$ in hybrid compensation, respectively.

In Figure 12a, the amplitude of the $5 \mathrm{th}, 7 \mathrm{th}$, and 11th harmonics of $i_{g}$ are $27.51 \mathrm{~A}$, $51.34 \mathrm{~A}$, and $4.90 \mathrm{~A}$, respectively. These harmonic currents are injected into the filter branch through spatial magnetic coupling, to change the filter branch current $i_{f}$.

In Figure 12b, the amplitude of the 5th, 7th, and 11th harmonics of $i_{f}$ are $39.92 \mathrm{~A}$, $29.54 \mathrm{~A}$, and $19.98 \mathrm{~A}$, respectively. The harmonic components $i_{f h}$ of $i_{f}$ in hybrid compensation includes the passive current component $i_{f h w}$ (the harmonic component when only 
the passive filter works) and the injected current component $i_{f h y}$ (injected by the active power filter).

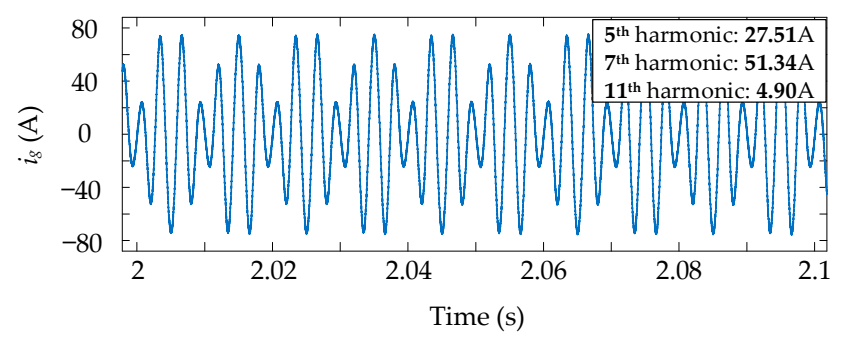

(a)

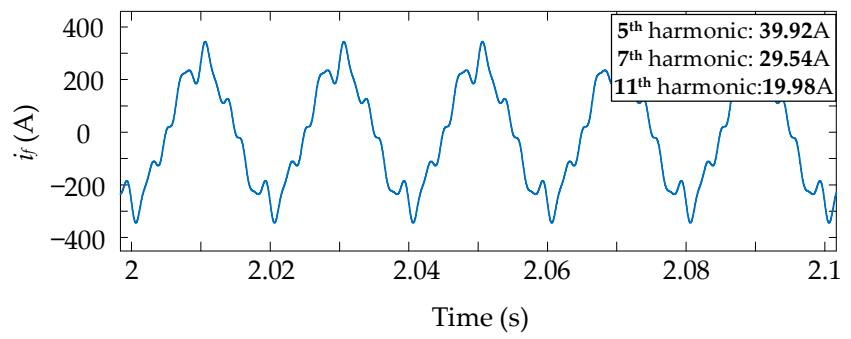

(b)

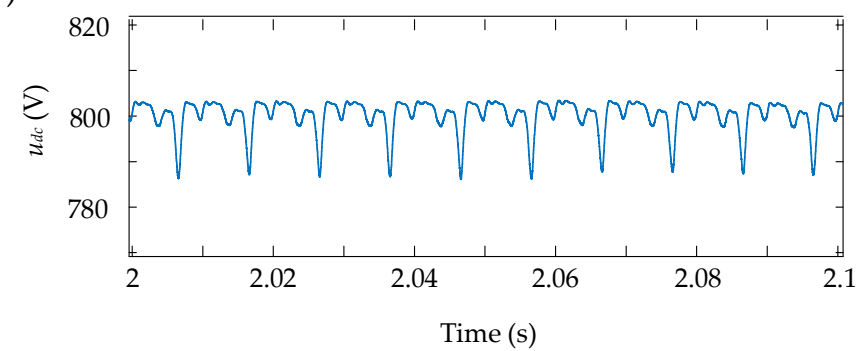

(c)

Figure 12. Compensation characteristic waveform. (a) Output current $i_{g}$ of the active power filter in hybrid compensation. (b) Filter branch current $i_{f}$ in hybrid compensation. (c) DC capacitor voltage $u_{d c}$ in hybrid compensation.

From Figure 12c, it can be seen that in hybrid compensation, the DC capacitor voltage $u_{d c}$ can be stabilized at $800 \mathrm{~V}$ with only small voltage fluctuations. The cause of the fluctuation is the active power exchange between the converter and the induced voltage $u_{g}$.

The apparent power of the active power filter can be calculated using the following equation:

$$
S_{A P F}=\frac{V_{d}}{\sqrt{2}} I_{g r m s}
$$

in which, $S_{A P F}$ represents the apparent power of the active power filter; $V_{d}$ represents the DC voltage of the active power filter; $I_{g r m s}$ represents the RMS value of the output current $i_{g}$.

In simulation, $V_{d}$ is $800 \mathrm{~V}$. $I_{g r m s}$ is $41.33 \mathrm{~A}$. So, the apparent power $S_{A P F}=23.38 \mathrm{kVA}$, according to (18).

The apparent power of the proposed HAPF can be calculated using the following equation:

$$
S_{H A P F}=U_{\text {Frms }} \cdot I_{\text {frms }}
$$

in which, $S_{\text {HAPF }}$ represents the apparent power of the proposed HAPF; $U_{F r m s}$ represents the RMS value of the voltage of the proposed HAPF; $I_{f r m s}$ represents the RMS value of the current $i_{f}$.

In simulation, $I_{\text {frms }}$ is $194.35 \mathrm{~A}$, and $U_{\text {Frms }}$ is $5845 \mathrm{~V}$. So, the apparent power $S_{\text {HAPF }}=$ $1135.975 \mathrm{kVA}$, according to (19).

$S_{P F}$ represents the apparent power of the passive filter. The ratio between $S_{A P F}$ and $S_{P F}$ is:

$$
K=\frac{S_{A P F}}{S_{P F}}=\frac{S_{A P F}}{S_{H A P F}-S_{A P F}}=\frac{23.38}{1135.975-23.38} \approx 2.10 \%
$$

It can be found that the capacity ratio of the active power filter to the passive filter in the proposed HAPF is very small. 


\subsection{Fault Simulation of the Active Power Filter}

The open-circuit and short-circuit fault diagram of the active power filter is shown in Figure 13. As is introduced before, the proposed HAPF has no additional coils in series connected to the passive filter branch, and the filtering effect of the passive filter will be guaranteed whether the active power filter is open or short-circuited. To verify this, simulations in two cases (open-circuit and short-circuit) are conducted.

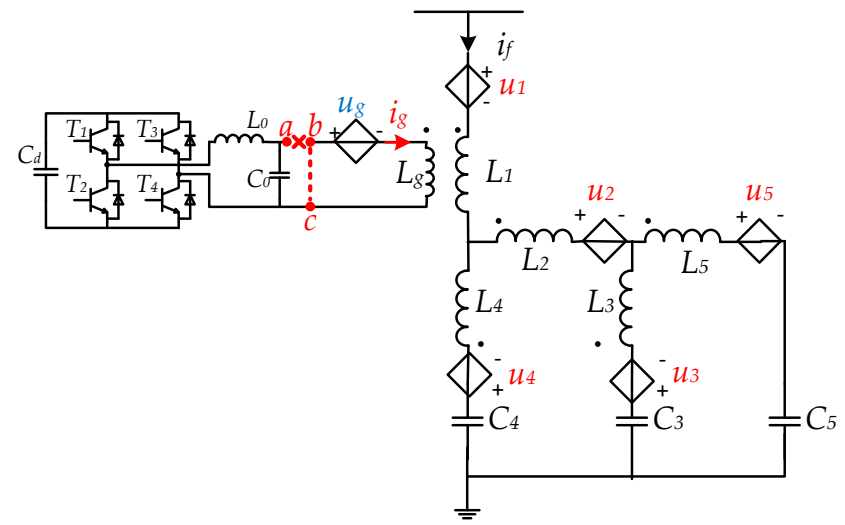

Figure 13. Open-circuit and short-circuit fault diagram of the active power filter.

According to Figure 13, under normal working condition, point $a$ and point $b$ are connected to each other, while point $b$ and point $c$ are not connected. When the connection between point $a$ and point $b$ is broken, the active power filter is open-circuited. At this time, the current $i_{g}$ is zero and the influence of the active power filter on the passive filter no longer exists. The open-circuit fault simulation result is shown in Figure 14a. Compared with the waveform of $i_{S}$ when only the passive filter works in Figure 11b, the waveform of $i_{S}$ in Figure 14a is almost the same.

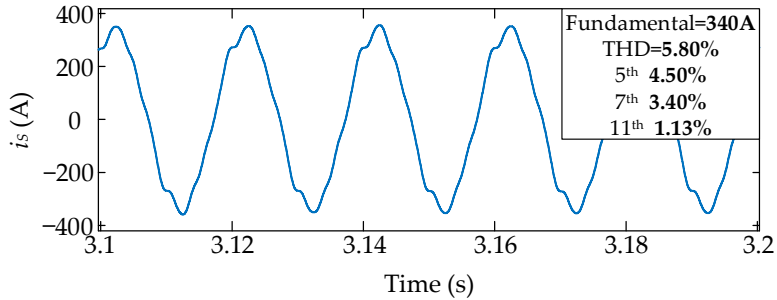

(a)

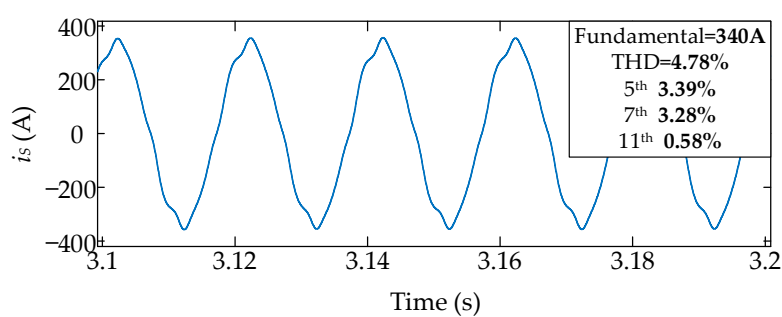

(b)

Figure 14. Supply current $i_{S}$ when the active power filter fails. (a) Supply current $i_{S}$ when the active power filter is open-circuited. (b) Supply current $i_{S}$ when the active power filter is short-circuited.

When point $b$ and point $c$ are connected, the active power filter is short-circuited. In this case, current $i_{g}$ is completely generated by the induced voltage $u_{g}$. At this time, the influence of the current $i_{g}$ on the passive filter is small. The short-circuit fault simulation result is shown in Figure 14b. Compared with the waveform in Figure 11b, the waveform of $i_{S}$ in Figure $14 \mathrm{~b}$ is very similar.

In summary, whether the active power filter is open-circuited or short-circuited, the filtering effect of the passive filter can be guaranteed.

\subsection{Simulation of Three-Phase Hybrid Active Power Filter}

To prove that the proposed HAPF topology is available for the three-phase system, a three-phase $10 \mathrm{kV}$ hybrid active power filter simulation was carried out. In the three-phase system, three single-phase hybrid active power filters are used. Each single-phase hybrid 
active power filter has the same topology and the same control strategy as described above. The parameters are the same as the parameters in Tables 1 and 2.

Figure 15 shows the waveforms of the supply current $i_{S}$ under different compensation strategies in the three-phase simulation. The waveform of $i_{S}$ without any compensation is shown in Figure 15a. The waveform of $i_{S}$ with passive compensation is shown in Figure 15b. The waveform of $i_{S}$ with hybrid compensation is shown in Figure 15c.

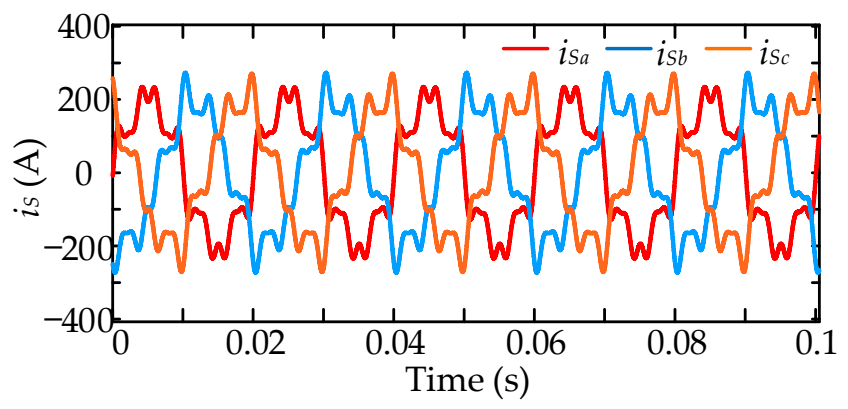

(a)

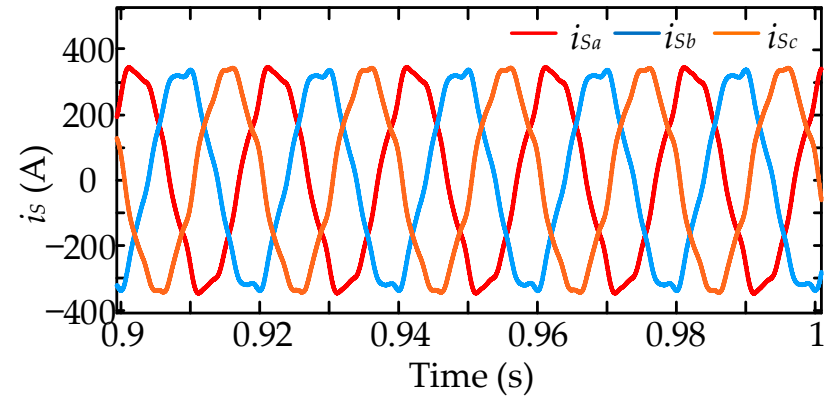

(b)

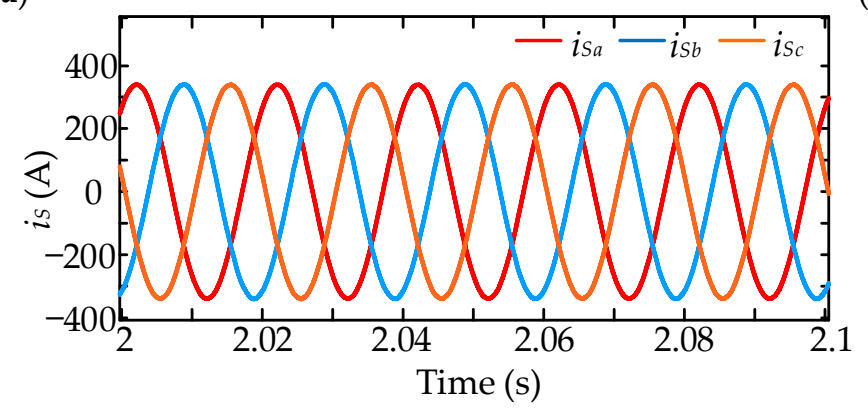

(c)

Figure 15. Supply current $i_{S}$ in three-phase system. (a) Supply current $i_{S}$ without any compensation. (b) Supply current $i_{S}$ when only the passive filter works. (c) Supply current $i_{S}$ with hybrid compensation.

In Figure 15a, taking phase A as an example, without any compensation, the THD of the supply current $i_{S a}$ is $26.29 \%$. The distortion of 5 th, 7 th, and 11 th harmonics of $i_{S a}$ is $19.56 \%, 14.64 \%$, and $9.71 \%$, respectively. In Figure $15 \mathrm{~b}$, with passive compensation, the THD of $i_{S a}$ is reduced to $5.81 \%$. Further, the distortion of 5 th, 7 th, and 11 th harmonics are $4.55 \%, 3.37 \%$, and $1.29 \%$, respectively. In Figure $15 \mathrm{c}$, with hybrid compensation, the THD of $i_{S a}$ is reduced to $0.29 \%$.

\section{Experiments}

In order to verify the feasibility of the proposed HAPF, a small prototype of multicoupled coils is designed and manufactured as shown in Figure 1b. Then, an experimental platform of the hybrid active power filter with multi-coupled coils is built according to the topology in Figure 4.

The structure schematic diagram of the HAPF experimental platform is shown in Figure 16. The platform is composed of the system power supply, harmonic source, and the proposed HAPF. The RMS value of the system voltage is transformed from $220 \mathrm{~V}$ to $36 \mathrm{~V}$ through a step-down transformer. The harmonic source is an adjustable harmonic current source. The HAPF with multi-coupled coils is composed of an active power filter and passive filter. The active power filter consists of the main circuit, detection circuit, and control circuit. 


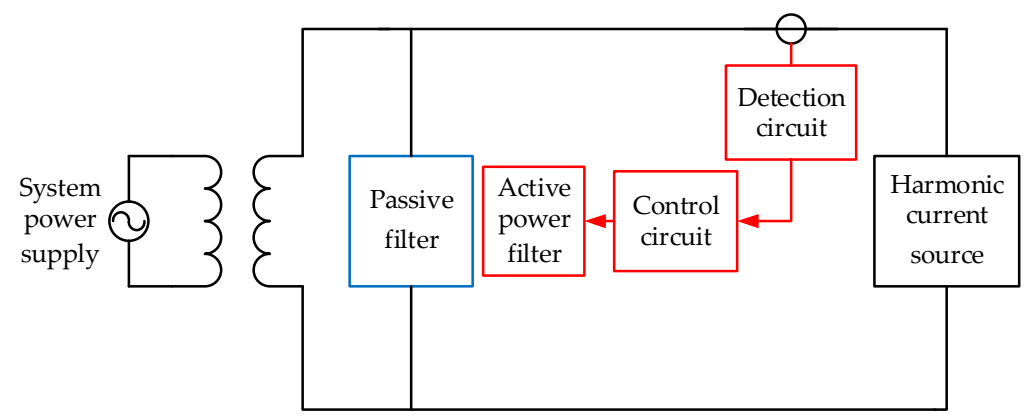

Figure 16. Structure schematic diagram of the HAPF experimental platform.

The experimental platform of HAPF with multi-coupled coils is shown in Figure 17. The main experimental parameters other than the inductance parameters of the multicoupled coils are shown in Table 3.

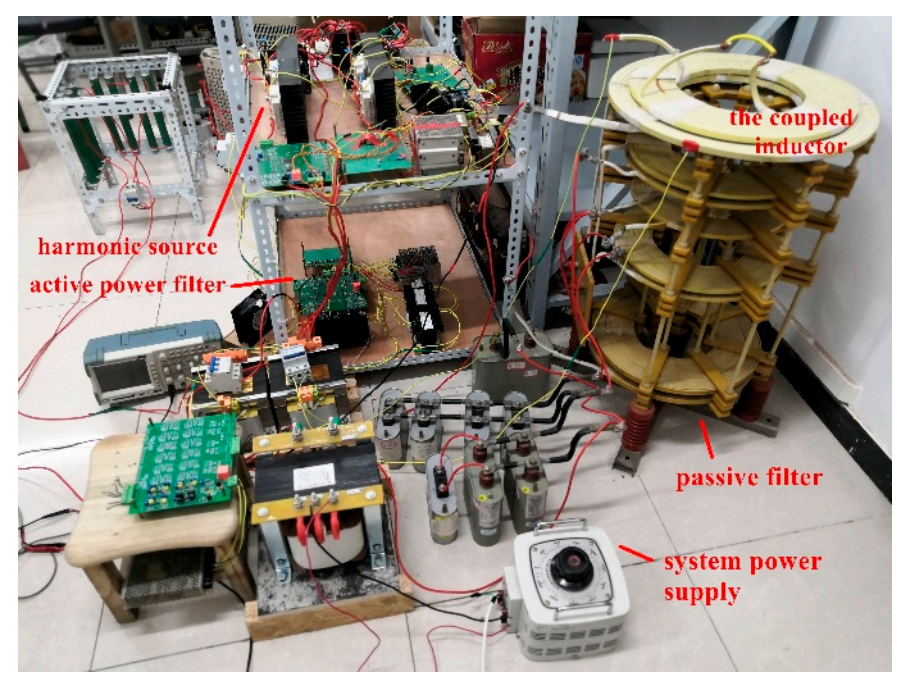

Figure 17. Experimental platform of HAPF with multi-coupled coils.

Table 3. Main experimental parameters.

\begin{tabular}{ccc}
\hline Categories & Variables & Value \\
\hline & voltage & $36 \mathrm{~V}$ \\
Supply-system parameters & frequency & $50 \mathrm{~Hz}$ \\
& $L_{S}$ & $0.12 \mathrm{mH}$ \\
Load harmonic parameters & amplitude of 3rd harmonic & $14.1 \mathrm{~A}$ \\
& $C_{3}$ & $352.9 \mu \mathrm{F}$ \\
Passive filter parameters & $C_{4}$ & $1269.7 \mu \mathrm{F}$ \\
& $C_{5}$ & $399.1 \mu \mathrm{F}$ \\
\hline
\end{tabular}

The inductance parameters of the multi-coupled coils in the platform are shown in Table 4.

Table 4. Inductance matrix of multi-coupled coils in experimental platform.

\begin{tabular}{ccccccc}
\hline Inductance $/ \boldsymbol{\mu H}$ & $\boldsymbol{L}_{\boldsymbol{g}}$ & $\boldsymbol{L}_{\mathbf{1}}$ & $\boldsymbol{L}_{\mathbf{2}}$ & $\boldsymbol{L}_{\mathbf{3}}$ & $\boldsymbol{L}_{\mathbf{4}}$ & $\boldsymbol{L}_{\mathbf{5}}$ \\
\hline$L_{g}$ & 980.0 & 155.0 & 37.1 & 258.8 & 13.2 & 45.9 \\
$L_{1}$ & 155.0 & 80.1 & 10.8 & 86.4 & 3.4 & 11.4 \\
$L_{2}$ & 37.1 & 10.8 & 106.8 & 90.2 & 9.0 & 57.5 \\
$L_{3}$ & 258.8 & 86.4 & 90.2 & 746.7 & 17.5 & 79.6 \\
$L_{4}$ & 13.2 & 3.4 & 9.0 & 17.5 & 872.8 & 62.7 \\
$L_{5}$ & 45.9 & 11.4 & 57.5 & 79.6 & 62.7 & 687.7 \\
\hline
\end{tabular}


The impedance-frequency characteristic of the passive filter in the experiment is measured by voltammetry as shown in Figure 18. From Figure 18, it can be seen that the measured tuned frequencies of the passive filter are $145 \mathrm{~Hz}, 247 \mathrm{~Hz}$, and $347 \mathrm{~Hz}$, which slightly deviate from the frequencies of the $3 \mathrm{rd}$, 5th, and 7 th harmonics.

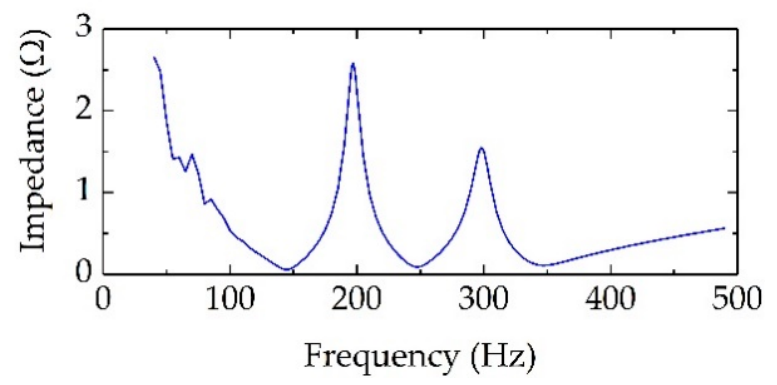

Figure 18. Measured impedance-frequency characteristic of the passive filter.

In the experiment, the load harmonic current source injects the 3rd harmonic current into the power grid, whose amplitude is $14.1 \mathrm{~A}$.

Figure 19 shows the experimental waveform of the supply current $i_{S}$ under different compensation strategies. The experimental waveform of $i_{S}$ without compensation is shown in Figure 19a. The experimental waveform of $i_{S}$ with passive compensation is shown in Figure 19b. The experimental waveform of $i_{S}$ with hybrid compensation is shown in Figure 19c.

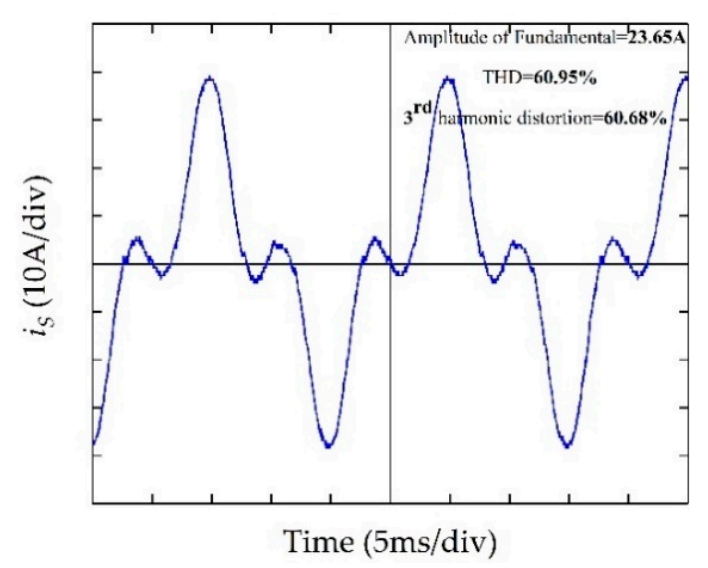

(a)

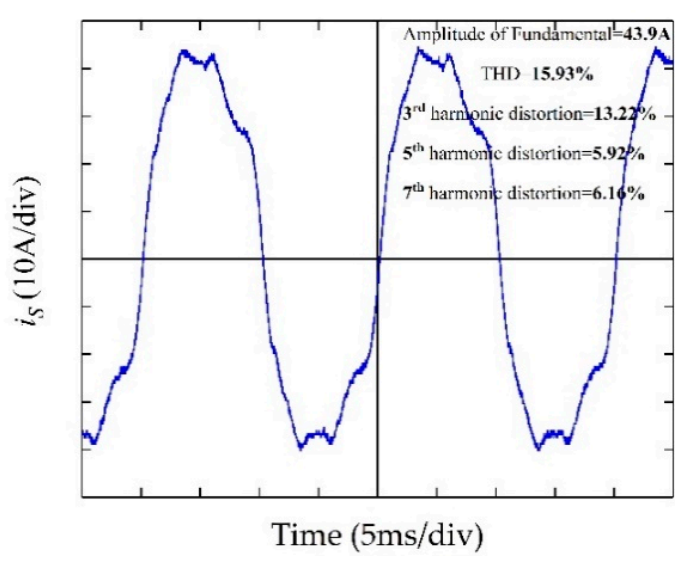

(b)

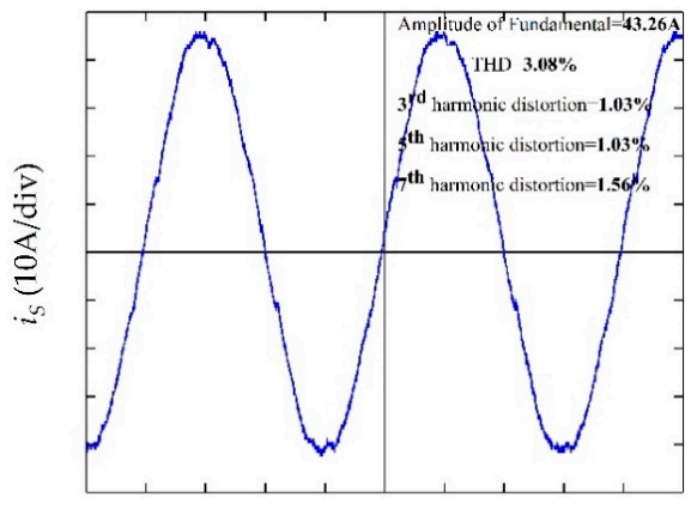

Time (5ms/div)

(c)

Figure 19. Supply current $i_{S}$ in the experiment. (a) Supply current $i_{S}$ without compensation. (b) Supply current $i_{S}$ with passive compensation. (c) Supply current $i_{S}$ with hybrid compensation. 
From Figure 19a, it can be seen that $i_{S}$ contains the obvious 3rd harmonic. The amplitude of the fundamental component of the supply current $i_{S}$ is $23.65 \mathrm{~A}$ and the THD is $60.95 \%$. The distortion of the 3rd harmonic of supply current $i_{S}$ is $60.68 \%$.

From Figure 19b, it can be seen that amplitude of the fundamental component of $i_{S}$ is $43.9 \mathrm{~A}$, which is larger than that before compensation because of the increase of capacitive fundamental current. The THD of $i_{S}$ is reduced to $15.93 \%$. The distortion of the 3rd harmonic is reduced to $13.22 \%$. At the same time, the distortion of the 5 th harmonic is $5.92 \%$, and the distortion of the 7 th harmonic is $6.16 \%$.

In passive compensation, the 5th and 7th harmonic currents appear in the supply current $i_{S}$, which is caused by the very small impedance of the system transformer in the experiment. For the 5th and 7th harmonics, the impedance of the passive filter branch is very small, so the 5th and 7th harmonics are introduced from the power grid.

From Figure 19c, it can be seen that the amplitude of the fundamental component of the supply current $i_{S}$ is $43.26 \mathrm{~A}$ and the THD is reduced to $3.08 \%$. The $3 \mathrm{rd}, 5$ th, 7 th harmonics of $i_{S}$ are greatly eliminated. Thus, it is reasonable to conclude that the proposed hybrid compensation method is feasible.

\section{Conclusions}

This paper proposes a novel hybrid active power filter with multi-coupled coils. The passive filter of the proposed HAPF adopts the structure of multi-coupled coils, which can reduce the required space of the inductors. The active power filter of the proposed HAPF adopts a coupled inductor instead of a transformer to connect with the passive filter. The active power filter can inject the compensation current into the passive filter branch through spatial magnetic coupling. At the same time, through spatial magnetic coupling, the active power filter can absorb active power from the passive filter branch to maintain the capacitor voltage.

To verify the effectiveness of the proposed scheme, a simulation model of a $10 \mathrm{kV}$ hybrid active power filter with multi-coupled coils is built in MATLAB/Simulink. Furthermore, an experimental platform of hybrid active power filter with multi-coupled coils is built. Simulations and experiments in this paper verify the feasibility of the proposed HAPF.

(1) The passive filter with multi-coupled coils can save the required space of the inductors on the premise of eliminating characteristic harmonics.

(2) The active power filter of the proposed HAPF can improve the filtering effect of the passive filter. The current injection through spatial magnetic coupling is effective and feasible.

(3) Since the connection method of spatial magnetic coupling, whether the active power filter is open-circuited or short-circuited, the filtering effect of the passive filter can still be guaranteed, which enhances the reliability of the filter.

In the simulation and experiment, it can be found that the inductance matrix of the multi-coupled coils directly affects the performance of the filter. Therefore, the parameter optimization of the multi-coupled coils is worthy of further research.

Author Contributions: Conceptualization, B.C., C.T. and Y.L.; methodology, Y.C., G.X. and J.Y.; software, G.X., Y.C.; validation, G.X., Y.Z. and G.C.; writing—original draft preparation, G.X.; writingreview and editing, G.X.; supervision, B.C. All authors have read and agreed to the published version of the manuscript.

Funding: This research received no external funding.

Data Availability Statement: The data presented in this study are available on request from the corresponding author.

Conflicts of Interest: The authors declare no conflict of interest. 


\section{References}

1. Bhattacharya, A.; Chakraborty, C.; Bhattacharya, S. Shunt compensation. IEEE Ind. Electron. Mag. 2009, 3, 38-49. [CrossRef]

2. Kanjiya, P.; Khadkikar, V.; Zeineldin, H.H. Optimal Control of Shunt Active Power Filter to Meet IEEE Std. 519 Current Harmonic Constraints under Nonideal Supply Condition. IEEE Trans. Ind. Electron. 2015, 62, 724-734. [CrossRef]

3. Badrzadeh, B.; Smith, K.S.; Wilson, R.C. Designing Passive Harmonic Filters for an Aluminum Smelting Plant. IEEE Trans. Ind. Appl. 2011, 47, 973-983. [CrossRef]

4. Li, X.; Xu, W.; Ding, T. Damped High Passive Filter-A New Filtering Scheme for Multipulse Rectifier Systems. IEEE Trans. Power Deliv. 2017, 32, 117-124. [CrossRef]

5. Chen, B.; Zhou, X.; Luo, Y.; Zhu, Y. Design of compact multi-tuned filter with coupled inductors. Electr. Mach. Control 2019, 23, 60-68. (In Chinese)

6. Sun, X.; Han, R.; Shen, H.; Wang, B.; Lu, Z.; Chen, Z. A Double-Resistive Active Power Filter System to Attenuate Harmonic Voltages of a Radial Power Distribution Feeder. IEEE Trans. Power Electron. 2016, 31, 6203-6216. [CrossRef]

7. Carpinelli, G.; Proto, D.; Russo, A. Optimal Planning of Active Power Filters in a Distribution System Using Trade-off/Risk Method. IEEE Trans. Power Deliv. 2017, 32, 841-851. [CrossRef]

8. Bosch, S.; Staiger, J.; Steinhart, H. Predictive Current Control for an Active Power Filter with LCL-Filter. IEEE Trans. Ind. Electron. 2018, 65, 4943-4952. [CrossRef]

9. Salmerón, P.; Litrán, S.P. A Control Strategy for Hybrid Power Filter to Compensate Four-Wires Three-Phase Systems. IEEE Trans. Power Electron. 2010, 25, 1923-1931. [CrossRef]

10. Corasaniti, V.F.; Barbieri, M.B.; Arnera, P.L.; Valla, M.I. Hybrid Active Filter for Reactive and Harmonics Compensation in a Distribution Network. IEEE Trans. Ind. Electron. 2009, 56, 670-677. [CrossRef]

11. Dey, P.; Mekhilef, S. Current harmonics compensation with three-phase four-wire shunt hybrid active power filter based on modified D-Q theory. IET Power Electron. 2015, 8, 2265-2280. [CrossRef]

12. Rahmani, S.; Hamadi, A.; Mendalek, N.; Al-Haddad, K. A New Control Technique for Three-Phase Shunt Hybrid Power Filter. IEEE Trans. Ind. Electron. 2009, 56, 2904-2915. [CrossRef]

13. Rahmani, S.; Hamadi, A.; Al-Haddad, K.; Dessaint, L.A. A Combination of Shunt Hybrid Power Filter and Thyristor-Controlled Reactor for Power Quality. IEEE Trans. Ind. Electron. 2014, 61, 2152-2164. [CrossRef]

14. Wang, L.; Lam, C.; Wong, M.; Dai, N.; Lao, K.; Wong, C. Non-linear adaptive hysteresis band pulse-width modulation control for hybrid active power filters to reduce switching loss. IET Power Electron. 2015, 8, 2156-2167. [CrossRef]

15. Wang, L.; Lam, C.; Wong, M. Unbalanced Control Strategy for A Thyristor-Controlled LC-Coupling Hybrid Active Power Filter in Three-Phase Three-Wire Systems. IEEE Trans. Power Electron. 2017, 32, 1056-1069. [CrossRef]

16. Wang, L.; Lam, C.; Wong, M. Selective Compensation of Distortion, Unbalanced and Reactive Power of a Thyristor-Controlled LC-Coupling Hybrid Active Power Filter (TCLC-HAPF). IEEE Trans. Power Electron. 2017, 32, 9065-9077. [CrossRef]

17. Tareen, W.U.K.; Mekhielf, S. Three-Phase Transformerless Shunt Active Power Filter with Reduced Switch Count for Harmonic Compensation in Grid-Connected Applications. IEEE Trans. Power Electron. 2018, 33, 4868-4881. [CrossRef]

18. Balasubramanian, R.; Parkavikathirvelu, K.; Sankaran, R.; Amirtharajan, R. Design, Simulation and Hardware Implementation of Shunt Hybrid Compensator Using Synchronous Rotating Reference Frame (SRRF)-Based Control Technique. Electronics 2019, 8 , 42. [CrossRef]

19. Shuai, Z.; Luo, A.; Zhu, W.; Fan, R.; Zhou, K. Study on a Novel Hybrid Active Power Filter Applied to a High-Voltage Grid. IEEE Trans. Power Deliv. 2009, 24, 2344-2352. [CrossRef]

20. Luo, A.; Shuai, Z.; Zhu, W.; Fan, R.; Tu, C. Development of Hybrid Active Power Filter Based on the Adaptive Fuzzy Dividing Frequency-Control Method. IEEE Trans. Power Deliv. 2009, 24, 424-432. [CrossRef]

21. Shuai, Z.; Luo, A.; Shen, J.; Wang, X. Double Closed-Loop Control Method for Injection-Type Hybrid Active Power Filter. IEEE Trans. Power Electron. 2011, 26, 2393-2403. [CrossRef]

22. Nguyen, T.N.; Luo, A.; Shuai, Z.; Chau, M.T.; Li, M.; Zhou, L. Generalised design method for improving control quality of hybrid active power filter with injection circuit. IET Power Electron. 2014, 7, 1204-1215. [CrossRef]

23. Zhou, X.; Chen, B.; Luo, Y.; Zhu, R. Analytical Calculation of Mutual Inductance of Finite-Length Coaxial Helical Filaments and Tape Coils. Energies 2019, 12, 566. [CrossRef]

24. Luo, Y.; Wang, X.; Zhou, X. Inductance Calculations for Circular Coils with Rectangular Cross Section and Parallel Axes Using Inverse Mellin Transform and Generalized Hypergeometric Functions. IEEE Trans. Power Electron. 2017, 32, 1367-1374. [CrossRef]

25. IEEE Guide for the Application and Specification of Harmonic Filters. In IEEE 1531, 2020 ed.; Institute of Electrical and Electronics Engineers (IEEE): New York, NY, USA, 2021; pp. 1-71. [CrossRef] 